and the guidelines touch on most of the controversial topics in largescale biology research today.

One of the key issues is when to share. The draft policy says that researchers must have shared their data by the time those data are published in a formal manuscript. However, there are earlier release deadlines for some data types, such as raw sequence data from nonhuman organisms and the initial analysis of some human sequence data, both of which must be shared within six months of submission to an approved repository. This is a thorny issue, and the NIH cannot please everybody. Some researchers favour the early release of more data, whereas others fear that releasing data ahead of publication will leave them vulnerable to being scooped.

Another major issue is how to protect the identity of those whose data are shared - especially as it is now clear that it is possible to identify people from anonymous data (see Nature http://doi.org/ px4; 2013). The guidelines say that researchers should tell study participants that their data "may be shared broadly for future research purposes", and let them know whether it will be shared through an open- or controlled-access mechanism. It asks researchers to gain explicit consent from patients who agree to share their data through open-access mechanisms. And, importantly, it sets a new bar for informed consent on de-identified materials, including cell lines and clinical specimens. Such research has historically been exempt from informed-consent requirements, but the guidelines ask researchers to obtain consent for future research on these materials, too.

This is a potentially major step, and one that this publication supports (see Nature 486, 293; 2012). It is true that some researchers who have relied on clinical specimens will see it as an impediment to valuable research. But similarly, some advocates of more transparent informed-consent rules will not like the fact that the guidelines allow researchers to opt out of this requirement if they give "compelling scientific reasons" for so doing.

A third aspect relates to how long the data should be shared for Researchers who rely on controlled-access data sets often complain about periodically having to renew their requests for access. The guidelines maintain this standard, offering access to such data for one year at a time. This is unlikely to please those who have argued that legitimate scientists should be able to access larger tranches of data and for longer periods of time - although the NIH has responded that

"This is a thorny issue, and the NIH cannot please everybody." scientists who take this position are sometimes not aware of the restrictions on all of the data sets that they plan to use (see Nature 497, 172-174; 2013).

Once finalized, the regulations will become part of a patchwork of international research regulation on the sharing of genomic data. The United Kingdom, for instance, is still deciding how much information from its $100 \mathrm{~K}$ Genome Project will be released and whether researchers will be able to access both sequencing results and the relevant personal health records. At the same time, US open-genomics evangelist George Church is expanding his Personal Genome Project to Canada and Europe, raising questions such as whether the project will be able to access records from centralized health systems (see go.nature.com/izmgpo). By contrast, informed-consent regulations in other parts of the world are still being developed, leaving a question mark over whether the United States will become an easier place for genomics researchers to work than other parts of the world.

In that context, the US proposals will have a major impact on the work of Nature's readers. Yet, according to the NIH's Office of Science Policy, as of 7 November, just 18 comments had been received on the guidelines. That is a poor response to such an important issue. The policy will affect many more scientists and Nature urges them to submit their responses to the proposals before the deadline of 20 November.

\section{Keep asking}

\section{Prejudice, not evidence, is too often the basis for government drug policies.}

$\mathrm{R}$ ob Ford, mayor of Toronto, Canada, caused a sensation last week when he told journalists, "Yes, I have smoked crack cocaine" - and refused to resign. The reporters smelled blood: Ford had long denied drug use, despite repeated rumours. "I wasn't lying," he said when confronted. "You didn't ask the correct questions."

The debate over the control and regulation of drugs is typified, perhaps more than any other in science policy, by a need to ask the correct questions. Politicians and the moralizing media tend to seek the black-or-white certainty of whether or not a drug poses a threat. Researchers often prefer to present risks as relative, and some argue that it is hypocritical to proscribe one compound while promoting, however tacitly, the consumption of another that may have similar or more potent - effects.

From time to time the answer changes because of other factors, and this is where the question becomes less important than who is asking it. The television drama Breaking Bad has brought the abuse of methamphetamine to popular attention, but the government of Japan, for example, has long been well aware of the drug's effects. In fact, during the Second World War it encouraged the manufacture of the compound and distributed it to the country's soldiers and civilian workers in a handy tablet form called hiropon. "For night work and other times demanding mental alertness. For overexertion," a typical wartime advert read. "The most powerful new amphetamine on the market!"

At the end of the war, Japanese manufacturers sold the stimulant as

a cure for all manner of civilian ills, targeting, among others, juveniles disturbed by the country's dramatic post-war social change. Yet within a few years, a government U-turn introduced tough laws making the drug illegal, with harsh penalties for possession. Official propaganda now called on citizens to help the authorities to "wipe out the evil of stimulant drugs!". Widespread abuse and signs of addiction gave the authorities a legitimate reason to act. But, as historian Jeffrey Alexander of the University of Wisconsin-Parkside pointed out in a paper this year (J. W. Alexander Int. J. Drug Policy 24, 238-243; 2013), there was another, more sinister motive: the deliberate cultivation of a media-fuelled drug panic to justify the arrest and deportation of Korean and Taiwanese immigrants, who were disproportionately blamed for making and selling methamphetamine.

Similar social pressures played a part in the crafting of US legislation against marijuana, which was first popular with Mexican labourers and black musicians. Prejudice is one of a number of issues contributing to policies on drugs that are explored by two books reviewed by Andrew Robinson on page 194. The books explain, he says, that "a drug's acceptability to mainstream society fluctuates more owing to social and cultural trends than to medical knowledge". For example, the United States infamously banned alcohol during the prohibition era of the 1920s and 1930s, a move that would have been unlikely in the United Kingdom because of the "complex British attitude to drunkenness".

This attitude was highlighted in 2009 by the UK government's then-drug adviser David Nutt, who argued publicly that alcohol and tobacco were more harmful than LSD, ecstasy and cannabis. His opinion earned him the sack. Last week, it also earned him the 2013

$\checkmark$ NATURE.COM To comment online, click on Editorials at: go.nature.com/xhunqv
John Maddox Prize for Standing Up for Science, which recognizes the promotion of science in the public interest, and was set up with the help of this publication. Someone has to keep asking the correct questions. 